\title{
A Literature Review of Empirical Research on Trade of Cultural Goods
}

\author{
Yanfen Wang ${ }^{1}$ \\ ${ }^{1}$ Doctoral student. School of Economics, Central University of Finance and Economics. Beijing. China \\ Correspondence: Yanfen Wang, Doctoral student. School of Economics, Central University of Finance and Economics. \\ Beijing. China.
}

Received: August 26, 2019

Accepted: September 16, 2019

Available online: November 8, 2019

doi:10.11114/afa.v6i1.4609

URL: https://doi.org/10.11114/afa.v6i1.4609

\begin{abstract}
UNESCO defines cultural goods as consumer products that spread ideas, symbols, and lifestyles. Cultural goods provide information and entertainment, which in turn form group identity and influence cultural behavior. The low energy dissipation, high added value and the property of value transmission of the cultural industry have made the cultural goods' status in the global trade higher annually. Meanwhile, the contribution made by cultural goods trade to the national economy has become increasingly prominent. This article provides accessible research directions and path for the follow-up study of Chinese cultural goods trade by reviewing the existing empirical research on the trade of cultural goods.
\end{abstract}

Keywords: cultural goods, trade, empirical research

\section{Introduction}

The current representative cultural goods trade theory includes the work by Janeba (2007), Rauch (2009), and Maystre (2014). The starting point of the research often is the network externality of cultural goods, and the ultimate goal usually ends up with its contribution to social welfare. The current empirical papers, especially China's empirical papers, seem to be somewhat inverted, they directly regress trade volume on some factors that affect the trade of cultural goods.

There are several important issues in those articles. (1) For the study of cultural goods trade, there is little research on network externalities --- the most important characteristics of cultural goods that differentiates itself from ordinary products, let alone verifying the existence of such effect; (2) Most empirical articles on trade in cultural goods apply gravitational models, but few researchers start from the theory of cultural goods trade to demonstrate the theoretical foundation of the gravity model; (3) Due to the strong social attributes of cultural goods, there are multiple control variables that affect the trade of cultural goods. However, why some of them are included in the model while others are not lacks clear explanation in most current studies.

\section{Empirical Research Literature of Western Cultural Goods Trade}

(1) Marvasti (1994) has noted that the protectionists in the world's trade of cultural goods, especially Canada and the European Union, setting many quota entries to limit the import of foreign (mainly American) film, television, radio, and other cultural goods. The main reasons for these countries to set up trade barriers for cultural goods can be summarized as two. One is to defend their cultural sovereignty. They don't want their cultural value orientation to be replaced or crushed. And the other reason is that those countries implement industrial support policies and want to form the economies of scale of domestic cultural goods, and then become a net exporter of cultural goods by cultivating the domestic cultural goods market. The main purpose of Marvasti (1994) is to prove whether the second purpose of cultural goods trade protection policy is valid.

The New Trade Theory is the theoretical foundation of industrial policy and trade protection policy, where the study of Marvasti (1994) takes root in. In the New Trade Theory, the relationship between net exports and market size (represented by population), labor-to-capital ratio, per capita income, and the relationship between trade policies (limits, subsidies, intellectual property rights), language, and religion are examined. The results show that the market scale plays a significant positive role in the net export of movies and records, and has no effect on books, newspapers, publications and other cultural goods. Therefore, Marvasti (1994) concluded that the scale economy proposed by New Trade Theory is not strong enough for implementing the policy of protection of cultural goods trade, and is not sufficient for opposing the free trade of cultural goods. 
As a relatively early paper, the argumentation and purpose of Marvasti (1994) are very meaningful, but the method is not correct. First, the measurement model lacks theoretical explanations and is constructed directly according to the conclusion of the New Trade Theory. Secondly, since the research focuses on the impact on the net export and the impact on the relative export of the scale economy, the explanatory variables should not take absolute values entirely. Because the regression of relative values on absolute values may result in bias. Finally, it is unreasonable to adopt the population to represent the market size which refers to the final purchase volume. Countries with large populations may not have a strong purchasing capacity. Therefore, the estimation effect of market size on net exports is not so convincing.

(2) Francois and Ypersele (2002) also study the protection policy of cultural goods trade. By constructing a game theory model, this paper demonstrates that cultural goods trade protection policies can bring welfare enhancement. However, the two most important limitations of the paper are: first, the production of cultural goods is increasing in scale, and second, cultural goods vary greatly across countries while other products remain constant. Focusing on the film trade between the United States and France, they find the game equilibrium without and with related taxes and then compare the two equilibrium results and draw the conclusion of the literature.

The main problem with this paper is that it is difficult to extend the conclusion from film to other cultural goods. The setting of it does not necessarily apply to other cultural goods (such as radio, television, literature or print media), so the conclusion needs to be further verified. However, it emphasizes that cultural goods have different values in different cultures and considers the heterogeneity of cultural goods, which is worthy of recognition and reference.

(3) Guiiso (2009) adpots the Eurobarometer questionnaire data from the European Union and extracts data on the individual trust report on foreign colleagues to study what factors lead to differences in trust. Culture plays an important role in this question. Trust itself is a kind of cognition of a country's culture. Furthermore, he estimates the impact of trust on international trade and international investment.

Explicitly, he examines the import and export influenced by trust and alleviates some inherent biases in the gravity model itself. For example, according to the gravity model, distance and language barriers are negative factors. However, there are some trades with high transportation costs and communication costs (that is, no common language used by both parties), which can be explained by the trust. Therefore, this article tells us that the degree of trust formed solely by the cultural cognition of a country has great effect on international trade.

(4) Disdier (2010) utilizes the trade data form the French Center for International Economic Research (CEPII). In this paper, the determinants of trade volume include factors such as language, colonization and geographical boundaries in the gravity model. The novelty of the article is to verify whether cultural goods trade promotes trade in non-cultural goods. Regressing trade in cultural goods directly on other trades variables may be problematic, even if time variable is controlled. As a result, there is still a strong reverse cause effect which results in higher biases.

He has a broad vision, which extends the trade of cultural goods which previously confined in the cultural industry to the relevance between the cultural industry and the non-cultural industry. Some other products also have the characteristics of cultural goods, such as the accumulation of consumer capital, product heterogeneity caused by cultural differences, the impact of consumer behavior on personal consumption, etc. However, they are less heterogeneous compared with cultural goods. Also, consumption in ordinary products requires less knowledge and is less susceptible to group behavior. The spillovers brought about by cultural goods have great externalities. Because ordinary commodities also have some weak network externalities, so the consumption behavior of other commodities will be affected by the consumption of cultural goods, so the verification in this area is very practical.

(5) Ferreira (2013) has studied the impact of the international trade of popular music on local music across half a century. The conclusion shows that there is no evidence that international pop music replaces local music, to the contrary, the number of people listening to local music has increased. Thanks to the current development of the Internet, the article collects data on national music rankings. And the author derives a gravitational model based on the available data and trade theory.

The empirical regression results show that, first of all, the proportion of trade in pop music trade against aggregate trade in each country is roughly the same; secondly, one country tends to import music products from other countries with similar geography and language. The pattern of material products is the same and there is no difference. Finally, the view that the big cultural entity dominates the small one through cultural goods trade is at least not applicable in the music field. The export volume of music in many countries is not in line with the economic volume.

This paper is of great significance for promoting the free trade of cultural goods. For nearly half a century, no country in the world has completely liberalized trade regulation on cultural goods. The biggest concern is that the culture from large foreign countries may impair local culture, resulting in the loss of cultural diversity of the world. There has been little literature that empirically examines the impact of cultural trade on cultural diversity. The reason was that "cultural 
diversity" could not be measured and there was no measurement standard. But this article argued that in the field of music, the spread of international music has not undermined local music, which can also be found in some modern new media industries.

For example, China imports great amounts of Korean entertainment industry products. At the same time, the mainland of China purchases and localizes many Korean copyrighted entertainment programs. China also imports video games from the United States and its domestic games are now growing and developing into independent production. In addition, China imports many well-made commercial film movies every year and now the National Day and Spring Festival box office champions are all domestic films. Therefore, this paper believes that in this era, the free trade of cultural goods can not only spread the values but also bring the communication technology of new media. The culture is very tenacious and will not be washed away when it is shocked. Instead, it can evolve and thrive with the help of the new communication technology.

\section{Empirical Research Literature of China's Cultural Goods Trade}

(1) Huo Bugang (2008) collected China's 2005 cultural trade data to test whether China's cultural goods trade matches Linder's (1961) overlapping demand theory (also called demand preference theory). The theory of overlapping demand states that the prerequisite for export is the great domestic demand. International trade is an extension of the domestic market. That is to say, when two countries have similar demand preferences, greater trade between them will occur, which also means that when the two countries have similar income levels, the trade volume will be greater. Huo Bugang (2008) conducted a regression with the trade volume between China and its trading countries in 2005 on the income levels of those countries. It is found that the overlapping demand trade theory could not explain the state of Chinese cultural trade well.

The theory of overlapping demand trade was first adopted to explain the model of trade within the manufacturing industry. Since the trade of cultural goods is different from the trade of ordinary goods, so there is a deviation. This paper argues that the explanatory power of overlapping demand trade theory has great limitations. For example, it cannot explain a large amount of trade between developed and developing countries, so it is not suitable for explaining the trade situation of Chinese cultural goods.

(2) Wang Wei (2008) measured the Trade Specialization Coefficient (TSI), Index of Intra-industry Trade (IIT) and Trade Intensity Index (TII) from 2001 to 2005 in China. The results show that the trade intensity between China and Japan or China and South Korea is very high. China's comparative disadvantages to South Korea and Japan are more prominent in the trade of printed products and literary works, movies, and pictures. And the gap in the areas of games, sports, and visual arts is relatively large.

He only does a simple job of processing and description of data, without any economic theory to explore and verify. The contribution is to portray the trade structure of China, Japan, and Korea. The Japanese comics industry and the game industry are relatively developed. South Korea's entertainment industry and film industry are relatively developed. Japan and South Korea's exports to China in these areas are consequences of the expansion of their local sales due to the prominent comparative advantage of those industries. However, China's great market size ensures that China's local market effect will continually increase, and China is promising to catch up with Japan and South Korea in these industries. Whether the local market effect of Chinese cultural goods trade has already experienced marginal improvement needs further scientific verification.

(3) Qu Ruxiao and Han Lili (2010) directly apply the gravity model with the export values as the explanatory variable, and GDP, GDP per capita, geographical distance, cultural distance, land area, trade conditions, technology level, language, free trade as the explanatory variables. In the calculation of cultural distance, Hofstede (1983) classifies cultural characteristics into four dimensions (power distance, uncertainty avoidance, individualism versus collectivism, masculinity versus femininity). Kogut and Singh (1988) define culture based on these four dimensions. The formula for calculating the distance is shown in equation (1):

$$
C D_{j}=\sum_{i=1}^{4}\left\{\frac{\left(I_{i j}-I_{i u}\right)^{2}}{V_{i}}\right\} / 4
$$

$I_{i j}$ represents the $i$-th cultural characteristics of the country $j . I_{i u}$ is the $i$-th cultural characteristics of country $u$. $V_{i}$ refers to the variance of the $i$-th cultural feature. Analyzing the cultural goods trade data between China and the top nine trading countries between 1999 and 2008, the study shows that the geographical distance harms the export of cultural goods. However, the cultural distance has a positive impact on exports. The sign of technological application is also positive, indicating that the export of Chinese cultural goods may mainly result from novelty-seeking, and the level of science and technology has not yet reached the level where foreign people want to learn Chinese culture through 
advanced online channels.

The study adopts the widely accepted cultural distance measurement method. Another merit is that different from all other documents that study the relations between cultural distance and trade, the results of it show positive correlation between them, that is, for some countries where cultural goods started relatively late, the early export drivers were cultural strangeness and curiosity. In addition, the relatively undeveloped cultural industries could not apply new media technologies to spread cultural goods more widely. However, one flaw is that it does not solve the reverse causal problem. As mentioned above, cultural distance can affect trade, and trade can also affect cultural distance. Therefore, if the reverse causal problem is not solved, the estimation result is biased.

(4) Meng Yinghua and Huang Ning (2012) also apply the gravity model, but the choice of explanatory variables is much simpler and rougher --- only GDP, population size, geographical distance and whether it is a member of the Free Trade Zone are included. However, one merit of the article is that regressions are conducted across the classifications of cultural goods separately. According to the UNESCO cultural goods classification (FCS), cultural goods are divided into eight categories (including cultural service products): cultural heritage (antique), performance and celebration goods (musical instruments), , visual arts and crafts (painting, photography, sculpture, handicrafts), publishing and print media (books and newspapers), audiovisual and new media (movies, games), design, tourism, sports.

The most desirable aspect of it is to treat cultural goods hierarchically, but the shortcomings are also obvious. Products such as design, tourism, sports are in the fuzzy zone where goods or service products are difficult to distinguish. Generally, they are not in the scope of economic research and is more classified as service products. However, since the empirical verification of the literature does not have any solid theoretical basis, it does not exclude cultural goods that cannot be explained by trade theory. Therefore, when classifying cultural goods trade, we must carefully select and screen data according to the interpretation of cultural goods trade theory.

(5) Liu Yang et al. (2013) also studied the potential factors affecting the trade of cultural goods. Although the reseach sample is only limited to OECD countries, it has overcome the problem of endogenous cultural distance to some extent. As mentioned, in the theory of cultural goods trade of Maystre (2014), cultural distances are highly endogenous---cultural distances can affect trade, and trade can, in turn, affect cultural distance. The article uses two indicators to overcome cultural distance endogeneity. One is the religious distance index constructed by Belot and Ederveen (2006). Religion mainly affects the trade of cultural goods by influencing the culture of the two countries. They also use the trade flow of cultural goods of reference country in 1998 as a cultural distance, which is equivalent to setting a reference value of the lag item as an instrumental variable.

The main two merits of the article are the exploration of the theoretical basis of the regression model. The Dixit-Stiglitz's monopolistic competition model, although it is not on the frontier of the research, is more theoretically solid than other literature that directly applys gravity model regression. The other one is to take into account consumption addiction as the characteristics of cultural goods and the concept of consumer capital accumulation. Drawing on the variable selection method of Eichengreen and Irwin (1998), the lagged one-period trade volume is used as the proxy variable for consumption addiction. The regression results show that cultural distance has a significant negative impact on cultural goods trade and consumption addiction dependence can last for 2-5 years.

(6) Shao Jun (2013) studied the impact of the construction of broadband infrastructure on the export of cultural goods. As one of the greatest inventions of the 21st century, the Internet has greatly reduced communication costs, expanded network effects, and facilitated and accelerated the accumulation of consumer capital. The study of the impact of broadband construction on cultural goods trade is in line with the characteristics of cultural goods, and to some extent, respond to the theory of cultural goods trade. Czernich et al. (2011) verified the relationship between broadband deployment and economic growth, using the number of people using fixed broadband per 100 people to represent the penetration of broadband, which is also adopted by Shao Jun (2013). At the same time, Czernich et al. (2011) used the existing telephone and cable television as instrumental variables to overcome the reverse causal problem, but Shao Jun (2013) did not solve the problem. Applying panel data from 150 countries and regions form 2000 to 2010 and using the fixed effect and random effect model, they show that the improvement of broadband infrastructure can promote the export of cultural goods.

The study provides a feasible path to study the impact of the modern Internet on the trade of cultural goods. The geometric multiple of the Internet has expanded the spread of network externalities, and it is difficult to measure the number of Internet users. Furthermore, the data of downstream users is in the hands of monopolies and not easy to obtain, but the second-best thing is that the data of broadband infrastructure is available, and can be used to verify network externalities. However, one thing to note is the strong reverse causality, because economic growth can accelerate the construction of broadband infrastructure, and the laying of broadband infrastructure is on the same pace with many economic indicators. Therefore, when using this indicator to perform estimation, the reverse causal relationship must be resolved first. 
(7) Qu Ruxiao and Yang Xiu (2015) collect the cultural goods trade data of China from 2000 to 2010 and select 8 major trading countries to verify the factor endowment effect or the local market effect, which is the main factor influencing trade size of Chinese cultural goods. The article revises the gravitational model in Schumacher and Silkistovs (2006), uses the capital-labor ratio to represent the factor endowment advantage, and presents the local market effect by the third industry added value. The regression results show that the local market effect has an increasing impact on trade volume and is gradually replacing the impact of factor endowment advantages.

This work draws on the essence of other methods used to study manufacturing trade drivers to verify the drivers of cultural goods trade. However, the problem lies in the fact that there is no in-depth study of the characteristics of cultural goods that are distinct from ordinary commodities. Secondly, there is no structural consideration of cultural goods, that is, the analysis is not delicate enough. This also indicates that research in this direction can be further advanced.

(8) Zhou Hongyan (2017) verified the local market effect of Chinese cultural goods trade, the estimation of which is conducted in static panel and dynamic panel model, respectively. The so-called dynamic panel model is to add the previous period of export value as an explanation in the regression model. Introducing "consumption addiction" into the model, they verify that the results are significant and robust, which means that the local market effect exists in the trade of cultural goods.

However, the theoretical framework of the local market effect adopted by it for cultural goods trade does not consider the characteristics of cultural goods, and directly selects the existing local market effect theory model which is applicable to all commodities, that is to say, the only contribution of it is to empirically verify the local market effect. However, it has been demonstrated by other literature throughly.

\section{Summary}

By reviewing the existing empirical research on cultural goods trade, this paper finds that (1) there are few documents focusing on the heterogeneity of cultural goods and the verification of heterogeneous features; (2) empirical analysis of cultural goods trade lacks theoretical foundation for estimation models; (3) the choice of control variables is also lack of support of economic theory.

Therefore, this paper believes that there is a need and space for the improvement of the study of cultural goods trade. Firstly, it is promising to explore the heterogeneity of cultural goods deeply and verify the heterogeneity characteristics. Secondly, the establishment of the measurement model with solid theoretical basis is needed. Finally, the control variables need to be chosen more carefully with the support of economic theory.

\section{References}

Disdier, A. C., Tai, S. H., Fontagné, L., \& Mayer, T. (2010). Bilateral trade of cultural goods. Review of World Economics, 145(4), 575-595. https://doi.org/10.1007/s10290-009-0030-5

Ferreira, F., \& Waldfogel, J. (2013). Pop internationalism: has half a century of world music trade displaced local culture? The Economic Journal, 123(569), 634-664. https://doi.org/10.1111/ecoj.12003

Francois, P., \& Van Ypersele, T. (2002). On the protection of cultural goods. Journal of International Economics, 56(2), 359-369. https://doi.org/10.1016/S0022-1996(01)00119-2

Huo, B. G. (2008). Empirical test of Chinese cultural trade deviation from demand similarity theory. Research on Financial and Economic Issues, 2008(7), 15-18.

Janeba, E. (2007). International trade and consumption network externalities. European Economic Review, 51(4), 781-803. https://doi.org/10.1016/j.euroecorev.2006.07.002

Liu, Y., Qu, R. X., \& Zeng, Y. P. (2013). What are the key factors affecting trade in cultural goods? Empirical evidence from OECD countries. International Trade Issues, 2013(11), 72-81.

Marvasti, A. (1994). International trade in cultural goods: A cross-sectional analysis. Journal of Cultural Economics, 18(2), 135-148. https://doi.org/10.1007/BF01078936

Maystre, N., Olivier, J., Thoenig, M., \& Verdier, T. (2014). Product-based cultural change: Is the village global? Journal of International Economics, 92(2), 212-230. https://doi.org/10.1016/j.jinteco.2013.10.005

Meng, Y. H., \& Huang, N. (2012). Determinants of Chinese cultural trade_ based on panel data of classified cultural goods. Finance and Trade Research, 2012(3), 40-48.

Qu, R. X., \& Han, L. L. (2010). An empirical study on the influencing factors of Chinese cultural commodity trade. China Soft Science, 2010(11), 19-31.

Qum R, X., \& Yang, X. (2015). Local market effect, factor endowment advantage and Chinese cultural goods Trade. Economics and Management Research, 2015(5), 22-30. 
Rauch, J. E., \& Trindade, V. (2009). Neckties in the tropics: a model of international trade and cultural diversity. Canadian Journal of Economics/Revue canadienne d'économique, 42(3), 809-843. https://doi.org/10.1111/j.1540-5982.2009.01528.x

Shao, J., \& Wu, X. Y. (2013). An Empirical Study on the Impact of Broadband Infrastructure on the Export of Cultural goods. International Economic and Trade Exploration, 2013(10), 38-47.

Wang, W. (2008). Empirical analysis of China, Japan and South Korea's cultural commodity trade. Heilongjiang Foreign Trade, 2008(6), 14-17.

Zhou, H. Y. (2017). Research on the Local Market Effect of Chinese Cultural goodss Trade, (Unpublished doctoral dissertation). Shandong University, Jinan, China.

\section{Copyrights}

Copyright for this article is retained by the author(s), with first publication rights granted to the journal.

This is an open-access article distributed under the terms and conditions of the Creative Commons Attribution license which permits unrestricted use, distribution, and reproduction in any medium, provided the original work is properly cited. 